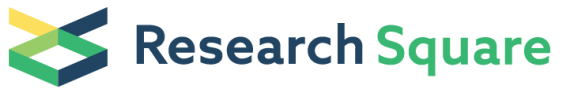 \\ Preprints are preliminary reports that have not undergone peer review. \\ They should not be considered conclusive, used to inform clinical practice, or referenced by the media as validated information.
}

\section{Epigenetic Events and Germ Line Transmission in Rag1 knock-out Chimeric Mice Produced by CRISPR/Cas9 Technology}

\section{Maryam Salimi}

Department of Biology and Anatomical Sciences, Faculty of Medicine, Shahid Beheshti University of Medical Sciences, Tehran, Iran

\section{Maryam Mehravar}

Reproductive Biotechnology Research Center, Avicenna Research Institute, ACECR, Tehran, Iran

\section{Abolfazl Shirazi ( $\nabla$ a.shirazi@ari.ir)}

Reproductive Biotechnology Research Center, Avicenna Research Institute, ACECR, Tehran, Iran

\section{Ali Sarvari}

Reproductive Biotechnology Research Center, Avicenna Research Institute, ACECR, Tehran, Iran

\section{Mohammad Mahdi Naderi}

Reproductive Biotechnology Research Center, Avicenna Research Institute, ACECR, Tehran, Iran

\section{Ali Malekpour}

Reproductive Biotechnology Research Center, Avicenna Research Institute, ACECR, Tehran, Iran

\section{Mohammad Mehdi Mehrazar}

Reproductive Biotechnology Research Center, Avicenna Research Institute, ACECR, Tehran, Iran

\section{Mohammad Majidi}

Department of Tissue Engineering \& Regenerative Medicine, Faculty of Advanced Technologies in Medicine, Iran University of Medical Sciences, Tehran, Iran

\section{Bahareh Behzadi}

Reproductive Biotechnology Research Center, Avicenna Research Institute, ACECR, Tehran, Iran

\section{Research Article}

Keywords: Chimeric Mice, CRISPR/Cas9, Epigenetic Events, Rag1 knocked out

Posted Date: February 15th, 2021

DOI: https://doi.org/10.21203/rs.3.rs-153876/v1

License: (c) (i) This work is licensed under a Creative Commons Attribution 4.0 International License. Read Full License 


\section{Abstract}

Considering the effects of epigenetic changes on the embryonic development through altering the gene expression of pluripotency, trophectoderm, and imprinting genes, we determined the pattern of epigenetic alterations in transgenic embryos produced by injecting transgenic mESCs into the morula. To aim this, RAG1 knock-out mESCs were produced using CRISPR-Cas9 editing system and then microinjected into morulas to develop chimeric embryos. Afterward, the expression of pluripotency, trophectoderm genes, and imprinting genes in these embryos were evaluated using real-time PCR. Immunohistochemical analysis was carried out to determine the methylation rates of $\mathrm{H} 3 \mathrm{~K} 9 \mathrm{me} 3$ and $\mathrm{H} 3 \mathrm{~K} 4 \mathrm{me}$. In the following, since epigenetic alterations can be at least one of the possible reasons of male infertility and the loss of germ-line transmission capacity, the germ-line transmission ability in chimeric mice was also evaluated by breeding them and subsequent backcrosses to wild type strains.

Our findings showed that the methylation rates of $\mathrm{H} 3 \mathrm{~K} 4 \mathrm{me} 3$ and $\mathrm{H} 3 \mathrm{~K} 9 \mathrm{me} 3$ were significantly lower and higher respectively in the RAG1 knock-out embryos compared others groups. Moreover, the chimeric embryos exhibited the decreased expression of NANOG, OCT4, CDX2, TEAD4, and H19 genes. Following the breeding of chimeric males with normal female mouse, $40 \%$ of chimeras had no germ-line transmission (GLT), and 60\% were infertile.

We showed that the manipulation of mESC by CRISPR-Cas9 approach remarkably changed the methylation status of $\mathrm{H} 3 \mathrm{~K} 9 \mathrm{me} 3$ and $\mathrm{H} 3 \mathrm{~K} 4 \mathrm{me} 3$, resulting in impaired development of embryos through dysregulation of genes involved embryonic development and then, may be one of the reasons of infertility and lack of GLT.

\section{Introduction}

Numerous studies are currently investigating the genomic changes in transgenic mice following introduction of foreign DNA into the embryos. Embryonic manipulation in the early stages of development, in which normal epigenetic changes occur, can induce interventions in these procedures. Tracing the fate of transfected DNA and its effect on the epigenetic status of the transfected embryos are extremely important. It has been observed that the entry of foreign DNA into the embryo's genome led to changes in DNA methylation and epigenetic features, which eventually affected the normal development of the transfected embryos. Epigenetic alterations, which is defined as changes in DNA levels without any changes in DNA sequence, profoundly influence gene expression (1-3). It is also reported that chromosome methylation will be increased in transgenic embryos produced by lentiviruses and retroviruses. It leads to changes in chromatin organization, inhibition of transcription, and expression of genes involved in embryo development (4-6). Increasing DNA methylation is a cell defense mechanism to counteract the entry of foreign DNA, similar to that normally happens in cells to avoid the entry of virus genomes. Following methylation, the acetylation of histones $\mathrm{H} 1$ and $\mathrm{H} 3$ also decreases. These epigenetic changes due to the entry of foreign gene lead to chromosome compaction and reduced expression of 
genes involved in embryonic development such as pluripotency, trophectoderm, and imprinting genes $(7,8)$.

To overcome problems regarding the use of viral vectors to develop transgenic embryos, new virus-free techniques such as CRISPR Cas9 have been successfully introduced.

However, the effect of this method on genome reprogramming and embryonic development needs to be further investigated. On the other hand, it should be noted that despite all the progress that has been made in the field of transgenic animal production, the production rate of these animal models is still low due to the lack of the best technique with the highest efficiency. Therefore, it is necessary to understand the molecular mechanism involved in reprogramming and development of transgenic embryos produced by CRISPR-Cas9.

To generate transgenic embryos, CRISPR/Cas9 components can be directly microinjected into zygotes without using ES cells and chimera generation or can be indirectly injected into ES cells and then according to the conventional method of producing germ-line transmitting chimeric mice, transgenic ES cells can be microinjected into pre-implantation embryos. This conventional method still offers some advantages over direct microinjection into zygotes, such as elimination of mosaicism in founders, and the ability to screen for the desired mutations before the creation of genome modified animals, etc $(9,10)$. Beyond that, in both approach embryonic manipulation in the early stages of development, in which normal epigenetic changes occur, can induce interventions in these procedures (11).

In this study, we investigated the epigenetic alterations of histone $\mathrm{H} 3$ and changes in the expression of pluripotency, trophectoderm, and imprinting genes in the RAG1 knocked-out transgenic blastocysts which were produced by the transfection of RAG1 knocked-out mouse embryonic stem cell (mESC) into the morulas. Furthermore, we evaluated the potential of transgenic embryos to produce chimeric mouse and germ-line competence. Since, chimera production and germ-line competence of the pluripotent mES cells may be influenced by the several factors such as a good epigenetic profile, mES cell line genetic background, euploid karyotype, etc (12).

\section{Results}

\section{Production of chimeric embryos:}

After the knock-out ES cells were confirmed to have normal morphology and pluripotency markers (data have been shown in our previous paper) (13), they were injected into morula and blastocysts. Blastocyst groups were cultured in KSOM medium and then used for subsequent examination using quantitative PCR and Immunohistochemical analysis, or production of chimeric mice.

\section{Methylation rates of H3K4me3 and H3K9me3 histones:}

According to our results, the methylation levels of $\mathrm{H} 3 \mathrm{~K} 9 \mathrm{me} 3$ histones were significantly higher in the the Rag 1 knocked out blastocysts than in the other experimental groups, while the Rag1 knocked out 
blastocysts showed the lower methylation rates of H3K4me3 compared with the sham and control groups Figure 1a, b).

\section{Real time PCR results:}

According to our findings, the Rag1 knocked out blastocysts exhibited lower expression levels of pluripotency genes including Nanog and Oct-4 compared with those blastocysts in the sham and control groups (Figure 2a). Our results also showed the lower expression rates of trophectoderm genes ( $C d x 2$ and TEAD-4) in the Rag1 knocked out blastocysts (Figure 2b).. We also found that the Rag 11 knocked out blastocysts expressed the $\mathrm{H} 19$ gene at a lower level than the sham and control groups, while there were no significant differences in the expression of Igf2 gene in all the 3 experimental groups (Figure 2c).

\section{Generation of chimeric mice and GLT results:}

After transferring chimeric embryos into the uterus recipients and pregnancy, it observed that male chimeric mice were produced more than females (Figure 3 ) (5 male chimera of 6 chimeric mice) but it was not a significant result, because the pregnancy rate and the overall number of newborn mice were small.

After breeding two of five male chimeras grade A (20 and 40\% coat color chimerism) with C57BL/ 6 female mice, all pups were black and according to the coat color and PCR results could not carry the RAG1 mutation. The breeding of the remaining three male chimeras grade $B(50,60$ and $70 \%$ coat color chimerism) did not result in pregnancy due to the infertility of these male chimeras that failed to produce sperm in testes.

\section{Male infertility due to lack of spermatogenesis:}

Infertile chimeras were examined for spermatogenesis and in the following, no sperm was observed in the vas deferens and epididymis. The reproductive components of male chimeras, including the testicles, epididymis and vas deferens, were removed and macroscopically examined. Testicular atrophy was observed in all male infertile chimeras and the epididymal and vas deferens components seemed almost normal (Figure 4a). For histological examination, the testes and epididymis were isolated, tissues were fixed in Bouin fixative and then the fixed paraffin-embedded, Hematoxylin and eosin-stained tissue blocks were prepared.

\section{Histological examination of the testes and epididymis of infertile chimeras:}

No spermatozoa were observed in seminiferous tubules and epididymal ducts. The seminiferous tubules were empty of all sperm, spermatids, spermatocytes and spermatogonia and they had only one layer of sertoli cells, unlike normal mice in which the seminiferous tubules were full of sperm and had several germ cell layers. The chimeras appeared to be the mixed group of germ cell aplasia syndrome and testicular atrophy (two subtypes of Primary testicular failure) (14) (Figure 4b). 


\section{Discussion}

Until now, the factors that affect the production efficiency of chimeric mice developed by embryonic stem cell injection technique have not been fully investigated. Numerous evidences suggest that the long-term culture conditions, in vitro genetic manipulation, and using endonuclease and lipofectamine enzymes may result in various genetic abnormalities or epigenetic alterations in the embryonic stem cells, which negatively influence the efficacy of the ESC injection method (15). Recent studies have shown that changes in epigenetic status of ESC cells injected to produce chimers led to altered gene expression, especially imprinting genes, in the developed embryos (16-17). In a study, injection of transposontransfected ESC remarkably changed the DNA methylation and consequently the expression of Igf2 and $\mathrm{H} 19$ genes, leading to serious disorders in embryos such as polyhydramnios and intestinal bleeding (18).

Recently, different animal models have been developed using CRISPR-Cas9 system by two approaches of direct injection into zygotes or indirect transfection into ES cells and chimera production, each with advantages and disadvantages over the other.

Despite the higher transfection and technical efficiency of this system compared to the ZFN and TALEN approaches, the live birth rate is still low, which indicates the development of genetic disorders following the use of such technique (19). There are also other problems including premature birth and defects in germ cells development and spermatogenesis in transgenic animals. Beside genetic disorders, epigenetic alterations alone can be at least one of the possible reasons for male infertility, interruption in germ cell development and loss of germ-line capacity, if no genetic abnormalities are detected (20).

It is reported that embryos developed by ICSI and SCNT methods and even frozen embryos showed a high rate of $\mathrm{H} 3 \mathrm{~K} 9 \mathrm{me} 3$ and me3H3K4 methylation. These genomic changes profoundly affected the gene expression levels in these embryos (21-23). The Me3 H3K4 accumulates at the transcription start site of genes involved in embryonic development such as pleuropotency genes, and its reduction leads to a decrease in the expression of genes such as Nanog, Oct4 and Sox2. Decreased expression of the Oct4 leads to downregulation of other transcription factors (24). Our results revealed that the level of H3K4me3 methylation in the chimeric RAG1 knocked-out embryos was significantly lower than those in the control and sham groups. As a result, the expression levels of pleuropotency genes (Nanog, Oct4), trophectoderm genes (TEAD4, CDX2), and $\mathrm{H} 19$ gene was significantly lower in the chimeric embryos compared with the other experimental groups. Unlike H3K4me3, H3K9me3 acts as an inhibitor at the transcription start site and increased $\mathrm{H} 3 \mathrm{~K} 9 \mathrm{me} 3$ methylation leads to downregulation of pleuropotency and imprinting genes (25). According to our findings, the methylation levels of $\mathrm{H} 3 \mathrm{~K} 9 \mathrm{me} 3$ in the chimeric embryos were significantly higher than in the sham and control groups. Over methylation of H3K9me3 elevated the heterochromatin formation in the RAG1-knocked out embryos which remarkably down regulated the expression of Oct4, Nanog, TEAD4, CDX2, and H19 genes. These findings were in line with those embryos produced by cloning method, in which culture media optimization was carried out to avoid devastating changes in developmental genes (26). 
It should be noted that the expression of IGF2 gene in the present study was lower in the chimeric embryos than those embryos in the sham and control groups, however, the differences were not significant. IGF2 is an important gene involved in normal development of embryos that shows a paternal expression pattern. Our results revealed that, unlike H19, the IGF2 gene is more resistant to epigenetic changes resulting from cell culture and gene manipulation.

The epigenetic changes in trophectoderm genes may occur due to manipulation and laser irradiation to zona pellucida during the injection of RAG1-knocked out into morula. Down regulation of trophectoderm genes is associated with several consequences including improper development of trophectoderm cells and placenta as well as the increased possible of miscarriage, premature birth, loss of germ-line transmission capacity, defects in germ cells development and spermatogenesis in these embryos. In the present study, male chimeras were either incapable of GLT or infertile. Although, genetic abnormalities are mainly responsible for infertility, miscarriage or inability in germ-line transmission, but in some cases, such defects could be related to epigenetic alterations occurring at different stages of spermatogenesis from when primordial germ cells migrate to the genital ridge until the transformation of the round spermatid. Therefore, There can be several justifications for the result of infertility or GLT inability, such as an unreliable epigenetic profile or other reasons, however, further clarifications is needed for finding exact mechanisms in the future experiments.

\section{Method And Material}

The study procedures were confirmed by the Research Ethics Committee of Shahid Beheshti University medical of Sciences, Tehran, Iran (IR.SBMU.MSP.REC.1395.5.1) Also all experiments were performed in accordance with relevant guidelines and regulations.

\section{Gene-targeted ES cells}

Biallelic RAG-1 knock-out mES clones (strain 129) had been produced using CRISPR/Cas9 gene editing system and cultured according to the protocols described in our previous work (13). Briefly, mESCs were grown on $0.1 \%$-gelatin-coated culture flask in the absence of feeder cells in mESC culture medium supplemented with R2i and 2\% ES-FBS. Transfection of mESCs was done using Lipofectamine 2000 according to manufacturer's instructions. Single clones of mESCs were obtained by serial dilution in 96well plates. After clone screening and validation, the pluripotent state of the mutant ES cells was confirmed by Quantitative analysis of pluripotency markers, Nanog, Oct4, and Sox2 genes (13).

\section{Animals}

This study was carried out in compliance with the ARRIVE guidelines. 6 to 8 weeks old C57BL6 (embryo donors), CD1 (recipients) and C57BL6 (breeders) mice were purchased from pasteur institute of Iran (Karaj, Iran).All strains were housed in standard conditions with a $12 \mathrm{~h}$ on/ $12 \mathrm{~h}$ off light cycle, 18 to $20^{\circ} \mathrm{C}$ temperature and standard mouse diet with autoclaved water. The care and use of all mice were approved by the animal care and use protocol of pasteur institute of Iran. 


\section{Media and chemicals}

Pregnant mare serum gonadotropin (PMSG) folligon was purchased from MSD Animal Health (www.msd-animal-health.co.in). Human chorionic gonadotropin (HCG/pregnyl) was directly purchased from pharmacies of Tehran (Tehran, Iran). M2 and KSOM embryo culture media, Polyvinylpyrrolidone (PVP360), Bovine serum albumin (BSA, embryo tested), Embryo culture-tested mineral oil, 1,4Dithiothreitol (DTT) and L-Glutamine were purchased from Sigma-Aldrich (www.sigmaaldrich.com). Trehalose dehydrate and skim milk were purchased from Merck (www.merckmillipore.com). Ketamine 10\% /Xylazine 2\% (Alfasan, Netherland) anesthetics mix was freshly prepared.

SYBR Premix Ex Taqll reagent (Takara Bio, Kusatsu, Shiga, Japan) was purchased from Takara (www.takarabio.com).

\section{Embryo collection and mESCs injection}

Six days prior to ES injection of embryos, superovulation of C57BL6 mice was induced by IP injection of $7.5 \mathrm{IU}$ PMSG and $48 \mathrm{~h}$ later, by IP injection of $7.5 \mathrm{IU} \mathrm{hCG}$. Blastocysts were collected from uterus on 3.5 pdc in M2 medium from natural mating of superovulated mice and Morulae were isolated from oviducts on 2.5 pdc. Collected embryos were cultured in KSOM medium with amino acids (KSOMaa) at $37^{\circ} \mathrm{C}$ in 5 $\%$ CO2 before mESCs injection.

Two days prior to ES injection, Rag1 knocked-out ES cells which had been stored in liquid nitrogen, were thawed and cultured in gelatin-coated flasks at $37^{\circ} \mathrm{C}$ in $5 \% \mathrm{CO} 2$.

ES injection of host blastocysts or morulae from C57BL6 strain was performed in M2 medium with 12-15 ES cells into blastocysts and 8-9 ES cells into morula using laser and micromanipulator.

\section{Experimental groups}

In the current study, the blastocysts isolated from natural mating were considered as the sham group. The control group included the blastocysts isolated from in vivo-derived morula, while the Rag1 knockedout blastocysts developed by microinjection of Rag1 knocked-out mESCs into the morula or blastocyst were defined as the test group.

The injected embryos in comparison with the non-manipulated embryos were evaluated for the expression of pluripotency, trophectoderm, and imprinting genes using real-time PCR and for the methylation rates of $\mathrm{H} 3 \mathrm{~K} 9 \mathrm{me} 3$ and $\mathrm{H} 3 \mathrm{~K} 4 \mathrm{me} 3$ using Immunohistochemical analysis.

A number of injected (Rag1 knocked-out) blastocysts were transferred into the uterus of recipients for producing chimeric mice and testing GLT.

\section{Real time PCR}


The real time PCR was performed to evaluate the expression levels of TEAD4, Oct-4, Cdx2, Nanog, H19, and Igf2 genes (Table.1). Total RNA was isolated from 5 blastocysts by the RNA extraction kite (Life Technologies, Gent, Belgium) based on the manufacturer's instructions. The RNA concentration of each sample was measured by a spectrophotometer (Pico drop Real-Life), and then, the extracted RNAs were suspended in $10 \mu \mathrm{l}$ of DEPC water and stored at $-80^{\circ} \mathrm{C}$, until they were used for CDNA synthesis. In the next step, cDNAs were synthesized based on the random hexamer approach using Prime Script Quanti Tect Kit (Qiagen, Hilden, Germany) according to the manufacturer's instruction. The following thermocycling condition was considered to synthesis cDNAs: 2 min at $42^{\circ} \mathrm{C}, 15 \mathrm{~min}$ at $42{ }^{\circ} \mathrm{C}$ followed by 3 min at $95^{\circ} \mathrm{C}$. Finally, the synthesized cDNA was stored at $20^{\circ} \mathrm{C}$.

\section{Immunohistochemical analysis:}

The blastocysts in each experimental group were fixed in $4 \%$ paraformaldehyde for $1 \mathrm{~h}$ at $4-8{ }^{\circ} \mathrm{C}$. Then, the blastocysts were placed at PBS containing $0.1 \%$ Tween 20 for 30 min and kept in $0.1 \%$ Triton at $4-8$ ${ }^{\circ} \mathrm{C}$. After washing, the blastocysts were placed in PBS containing $2 \% \mathrm{BSA}$ and kept in incubator for $1 \mathrm{~h}$ to black antigens of blastocysts. At the next step, the blastocysts were treated with the primary antibodies for $1 \mathrm{~h}$ at the room temperature, followed by $1 \mathrm{~h}$ incubation with the secondary Alexa Flour 594 antibodies at the incubator. Finally, the cell nucleuses were stained using DAPI.

\section{Gene expression evaluation}

Following cDNA synthesis, the real time PCR was carried out on CDNA samples using SYBR Premix Ex Taqll reagent (Takara Bio, Kusatsu, Shiga, Japan) to measure the expression rate of the genes involved in embryonic development. Thermal cycling was carried out on a Rotor-Gene Q instrument (Qiagen, Hilden, Germany) under the following conditions: $30 \mathrm{~s}$ at $95^{\circ} \mathrm{C}, 50$ cycle of $5 \mathrm{~s}$ at $95^{\circ} \mathrm{C}, 30 \mathrm{~s}$ at $60^{\circ} \mathrm{C}, 60$ to $95^{\circ} \mathrm{C}$ with a ramp rate of $0.3^{\circ} \mathrm{C} / \mathrm{s}$ as melting curve. To normalize the relative expression rates of the aforementioned genes, the expression of $\mathrm{H} 2 \mathrm{afz}$ and GAPDH were measured as the housekeeping genes. The REST software was used to analyze the results and $p \leq 0.05$ was considered to be meaningful.

\section{Chimera production, breeding and GLT testing}

After injecting embryos, they were transferred into the uterus of $2.5 \mathrm{dpc} C D 1$ recipients in order to produce chimeric mice. Chimeras were examined at 12 days of age for coat chimerism.

For testing GLT, male chimera at 8 weeks of age were bred with wildtype female C57BL/6N mice (male chimera are set with two females per cage). This process was repeated several times for each male chimera. In the case of successful pregnancy and delivery, pups were assayed for the agouti dominant coat color and RAG1 mutation analysis by PCR and Sanger sequencing for the presence of mutations. If the agouti coat color was not observed in 40 pups per male chimera, it indicates that the RAG1 knockout ES cell did not participate in the germ cell layer, so GLT was not successful.

In the absence of pregnancy after 4 weeks, females were replaced with new females. If pregnancy did not occur after 50 days, male chimera infertility in comparison with a fertile male was assessed by sperm 
collection and analysis of quality and genotype of collected sperms.

\section{Sperm collection, DNA extraction and PCR reaction}

Male mice were anesthetized with appropriate dose of ketamine and xylazine. After incision at the site around the base of the penis, the fat pad with the testicles, epididymis and vas deferens, were pulled out. Then, using a transfer needle (internal diameter of $120 \mu \mathrm{m}$ ), connected to the injection pump, the sperm sample was removed after inserting a small amount of PBS buffer into the vas deferens. If the vas deferens tubes were empty of sperm, the sample was expelled from cauda epididymis. Sperm samples were emptied into a tube containing PBS buffer. Sperm morphology and motility were assessed under the phase contrast microscope.

Sperm DNA extraction was performed according to a simple improved kit-based protocol in which DNA extraction was efficient even from a small amount of sperm ( 20,000 sperms) (Figure 5, Figure S5).

In this method, sperm samples diluted in PBS to a final volume of $200 \mu \mathrm{L}$. Sperm suspensions were pulse-vortexed for $5 \mathrm{~min}$ in $200 \mu \mathrm{L}$ lysis buffer (Favorgen Biotech, taiwan) with additives including reducing agent DTT (final concentration: $150 \mathrm{mM}$ ), 0.5\% Triton X-100 and Proteinase $\mathrm{K}$ (final concentration: $200 \mu \mathrm{g} / \mathrm{mL}$ ), then incubated at $56^{\circ} \mathrm{C}$ for $4 \mathrm{~h}$ and vortexed vigorously every $1 \mathrm{~h}$. In the following, DNA extraction was performed according to the protocol of DNA isolation kit (Favorgen Biotech) and PCR reaction was performed with RAG-1 primers (forward primer: GAA GAA GCA CAG AAG GAG AAG, reverse primer: ATC GGC AAG AGG GAC AAT AGC) under the same condition described in previous protocol (13).

\section{Sperm cryopreservation}

Sperm cryopreservation in Cryoprotective medium (12\% trehalose dehydrate, $3 \%$ skim milk, $100 \mathrm{mM} \mathrm{L-}$ Glutamine) was performed in liquid nitrogen according to the protocol described by Takeo et al. (14). Briefly, $100 \mu \mathrm{l}$ of Cryoprotective medium was poured onto the epididymis, several incisions were made in the cauda epididymis and the plate was shacked and incubated at $37^{\circ} \mathrm{C}$ for $10 \mathrm{~min}$ in order to release sperms into the medium. The entire medium containing the sperm was then collected and transferred to the freezing straws. The sperm straws were placed above liquid nitrogen for 10 minutes and quickly plunged in the liquid nitrogen. After a few days, in order to assess the viability and motility of the frozen sperms, sperm straws were removed from the liquid nitrogen and immersed in $37^{\circ} \mathrm{C}$ water for 10 minutes. Almost right after thawing cryopreserved C57BL/ 6 mouse sperms as control, $30 \%$ of sperms were highly mobile and the viability was $40 \%$.

\section{Declarations}

Funding: This research did not receive any specific grant from funding agencies in the public, commercial, or not-for-profit sectors.

\section{Acknowledgment:}


The all authors would like to acknowledge the faculty of Behrouz Farhadihosseinabadi, Also Reproductive Biotechnology Research Center, Avicenna Research Institute, ACECR, for providing the possibility of doing the study and their technical supports and University of Medical Sciences for helpful assistance.

\section{Notes on contributors:}

A.S.; conceived and supervised the research and its design, performed embryo microinjection. M.S., M.M.; designed and performed the experiments, interpreted the data and wrote the manuscript. A.S., M.M.N.; Assigned reagents/materials/analytical tools, performed the experiments of embryo transfer. M.M.M.; designed the experiments, interpreted the data. M.M., A.M., B.B; Executed the experiments, data collection and analyzed the data. All authors approved the final manuscript.

Conflict of Interest: The authors declare no conflict of interest.

Data availability statement: The data that support the findings of this study are available from the corresponding author upon reasonable request.

\section{Ethical Statements:}

The study procedures were confirmed by the Research Ethics Committee of Shahid Beheshti University medical of Sciences, Tehran, Iran (IR.SBMU.MSP.REC.1395.5.1). Also all experiments were performed in accordance with relevant guidelines and regulations

ARRIVE guidelines Statement: The authors declare that this study was carried out in compliance with the ARRIVE guidelines.

\section{References}

1. McCreath KJ, et al. Production of gene-targeted sheep by nuclear transfer from cultured somatic cells. Nature 405 (6790):1066-9. https ://doi.org/10.1038/35016604. (2000)

2. Denning C, et al. Gene targeting in primary fetal fibroblasts from sheep and pig. Cloning Stem Cells 3(4):221-31. https ://doi.org/ 10.1089/15362300152725945 (2001).

3. Santos F, Dean W. Epigenetic reprogramming during early development in mammals. Reproduction 127 (6):643-51. https ://doi.org/10.1530/rep.1.00221.(2004)

4. Perecin F, et al. 187 IMPRINTED GENE EXPRESSION IN IN VIVO-AND IN VITRO-PRODUCED BOVINE FETUSES AND PLACENTAS. Reprod Fertil Develop 20(1):173. https://doi.org/10.1071/RDv20n1Ab187 (2007)

5. Kosaka Y, et al. Lentivirus-based gene delivery in mouse embryonic stem cells. Artif Organs 28(3):271-7. https ://doi.org/10.1111/j.1525-1594.2004.47297.x.)2004)

6. Hofmann A, et al. Epigenetic regulation of lentiviral transgene vectors in a large animal model. $\mathrm{Mol}$ Ther13(1):59-66. https ://doi.org/ 10.1016/j.ymthe.2005.07.685. (2006) 
7. Park SH, et al. $\mathrm{CpG}$ methylation modulates tissue-specific expression of a transgene in chickens. Theriogenology 74(5):805-16. e1. https ://doi.org/ 10.1016/j.theriogenology.2010.04.005(2010).

8. Jähner $D$, et al. De novo methylation and expression of retroviral genomes during mouse embryogenesis. Nature 12; 298(5875):623-8. https ://doi.org/10.1038/298623a0. (1982)

9. M. Mehravar, A. Shirazi, M. Nazari, M. Banan, Mosaicism in CRISPR/Cas9-mediated genome editing, Dev Biol 445(2): 156-162. https ://doi.org/ 10.1016/j.ydbio.2018.10.008.( 2019)

10. Y. Du, W. Xie, F. Zhang, C. Liu. Chimeric Mouse Generation by ES Cell Blastocyst Microinjection and Uterine Transfer, Microinjection, Methods Mol Bio/ 1874:99-114. https ://doi.org/10.1007/978-14939-8831-0_6.(2020)

11. T. Kohda, Effects of embryonic manipulation and epigenetics. J Hum Genet 58(7): 416-420. https://doi.org/10.1038/jhg.2013.61. (2013)

12. A.C. Carstea, M.K. Pirity, A. Dinnyes, Germline competence of mouse ES and iPS cell lines: Chimera technologies and genetic background, World J Stem Cells 1(1): 22-29. https ://doi.org/10.4252/wjsc.v1.i1.22. (2009)

13. M. Mehravar, et al. Efficient Production of Biallelic RAG1 Knockout Mouse Embryonic Stem Cell Using CRISPR/Cas9, Iran J Biotechno/ 11;17(1):e2205. https ://doi.org/10.21859/ijb.2205. (2019)

14. A. Halder, P. Kumar, M. Jain, A.K. Kalsi, Genomics: Tool to predict and prevent male infertility. Front Biosci 9: 448-508. https ://doi.org/10.2741/s496. (2017)

15. . Ibon Garitaonandia, et al. Increased Risk of Genetic and Epigenetic Instability in Human Embryonic Stem Cells Associated with Specific Culture Conditions. Plos One; 10(2):e0011830. https ://doi.org/ 10.1371/journal.pone.0118307. (2015)

16. Reik W. and Walter,J. (2001) Evolution of imprinting mechanisms: the battle of the sexes begins in the zygote. Nat Genet 27(3):255-6. https ://doi.org/10.1038/85804. (2001)

17. Feinberg A.P. Imprinting of a genomic domain of $11 \mathrm{p} 15$ and loss of imprinting in cancer: an introduction. Cancer Res 1999; 59 (7 Suppl):1743s-1746s.

18. Wendy Dean, et al. Altered imprinted gene methylation and expression in completely ES cellderived mouse fetuses: association with aberrant phenotypes. Development 1998; 125(12); 2273-2282

19. Sato T, et al. Genome editing in mouse spermatogonial stem cell lines using TALEN and doublenicking CRISPR/Cas9. Stem Cell Reports 5: 75-82 https ://doi.org/10.1016/j.stemcr.2015.05.011. (2015)

20. T. Takeo, N. Nakagata, Mouse sperm cryopreservation and effective embryo production using cryopreserved C57BL/6 mouse sperm. J Mamm Ova Res 27(3): 70-78. https ://doi.org/10.1274/jmor.27.70. (2010)

21. Niemann $\mathrm{H}$, Tian XC, King WA, Lee RS. Epigenetic reprogramming in embryonic and foetal development upon somatic cell nuclear transfer cloning. Reproduction 135(2):151-63. https ://doi.org/10.1530/REP-07-0397.(2008) 
22. Farahavar A, et al. Improving the quality of ovine embryo produced in vitro by culturing zygote in isolated mouse oviduct. Small Ruminant Res 161:1-6. https

://doi.org/10.1016/j.smallrumres.2017.11.004. (2018)

23. grawal $\mathrm{H}$, et al. Epigenetic alteration of donor cells with histone deacetylase inhibitor $\mathrm{m}$ carboxycinnamic acid bishydroxymide improves the in vitro developmental competence of buffalo (Bubalus ubalis) cloned embryos. Cell Reprogram 20(1):76-88. https ://doi.org/10.1089/cell.2017.0035. (2018).

24. Bernstein $\mathrm{BE}$, et al. A bivalent chromatin structure marks key developmental genes in embryonic stem cells. Cel/ 125(2):315-26. https ://doi.org/10.1016/j.cell.2006.02.041. (2006)

25. Lee $\mathrm{Tl}$, et al. Control of developmental regulators by Polycomb in human embryonic stem cells. Cell 125(2):301-313. https ://doi.org/10.1016/j.cell.2006.02.043. (2006)

26. Chen P, et al. Effect of BIX-01294 on H3K9me2 levels and the imprinted gene Snrpnin mouse embryonic fibroblast cells. Biosci Rep 35(5): e00257. https ://doi.org 10.1042/BSR20150064. (2015)

\section{Tables}

Table 1. The list of primer sequences 


\begin{tabular}{|c|c|c|}
\hline Genes name & Primer sequences ( $\left.5^{\prime}-3^{\prime}\right)$ & $\mathrm{Tm}$ \\
\hline \multirow[t]{2}{*}{ GAPDH } & Forward: TTCCAGTATGATTCCACCCAC & 55.9 \\
\hline & Reverse: ACTCAGCACCAGCATCACC & 55.7 \\
\hline \multirow[t]{2}{*}{$\mathrm{H} 2 \mathrm{afz}$} & Forward: CTCGTCTCTTCCTCGCTCGT & 61.3 \\
\hline & Reverse: CGTCCGTGGCTGGTTGTC & 61.04 \\
\hline \multirow[t]{2}{*}{ Nanog- } & Forward: CTGAGGAGGAGGAGAACAAGGTC & 58 \\
\hline & Reverse: CATCTGCTGGAGGCTGAGGTA & 60 \\
\hline \multirow[t]{2}{*}{ Oct- 4} & Forward: CGTGTGAGGTGGAGTCTGGA & 58.7 \\
\hline & Reverse: GCTGATTGGCGATGTGAGTG & 59.4 \\
\hline \multirow[t]{2}{*}{$\operatorname{lgf} 2$} & F: TGTGAGCAAGCGACGGAGT & 58.3 \\
\hline & R: GGATTCAGTGGCTGGCAGA & 58.6 \\
\hline \multirow[t]{2}{*}{$\mathrm{H} 19$} & F: TGAAGGCGAGGATGACAGGT & 58.9 \\
\hline & R: TCCAGAGAGCAGCAGAGAAGTG & 60 \\
\hline \multirow[t]{2}{*}{ TEAD-4 } & F: CGGAGGAAGGCAAGATGTATG & 55.9 \\
\hline & R: ACCTGGATGTGGCTGGAGAC & 55.7 \\
\hline \multirow[t]{2}{*}{$\mathrm{Cdx} 2$} & F: GCTGCTGTAGGCGGAATGTAT & 57.9 \\
\hline & R: CTCCCGACTTCCCTTCACC & 57 \\
\hline
\end{tabular}

Figures 
a



b

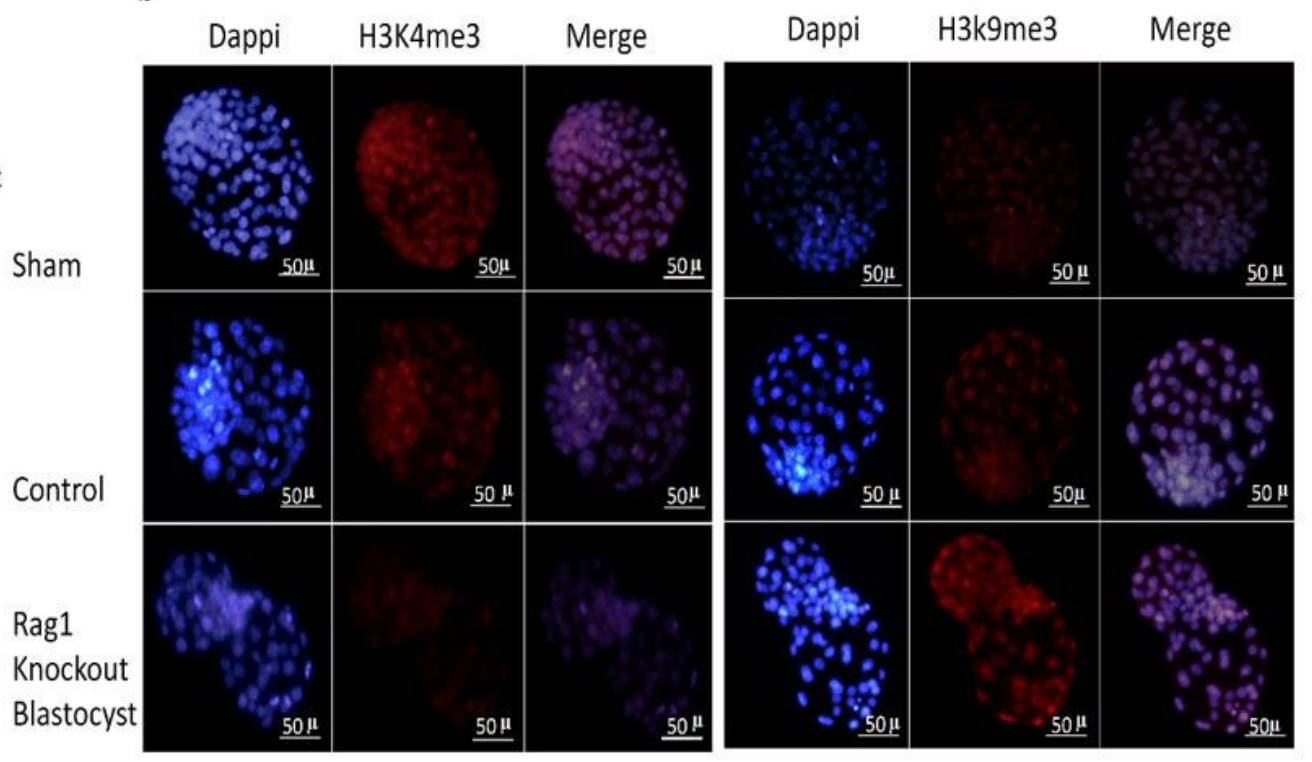

\section{Figure 1}

Three methylation of $\mathrm{H} 3 \mathrm{~K} 4$ and $\mathrm{H} 3 \mathrm{~K} 9$ as well as gene expressions in the all experimental groups 1 .

Sham: Blastocysts obtained from natural mating, 2. Control: Blastocysts derived from cultured of $2.5 \mathrm{Dpc}$ embryo, 3. Rag 1 Knockout Blastocyst: blastocysts derived from microinjected Rag 1 Knockout mESCs to $2.5 \mathrm{Dpc}$ embryo. Data are shown as mean \pm SD ( $: p \leq 0.05$ ); (a) Relative levels of global H3K9me3 and H3K4me3 in nucleus (mean \pm SEM), ( $*$ : $p \leq 0.05$ ); (b) Immunocytochemistry staining of H3K4me3 and H3K9me3. The nuclei (blue) were stained with DAPI. H3K4me3 and H3K9me3 protein were stained with using anti-mouse IgG (red). The merged images of H3K4me3 and H3K9me3 with DNA are purple. Scale bars: $50 \mu$; 
a


\section{Figure 2}

The real time PCR was performed to evaluate the expression levels of TEAD4, Oct-4, Cdx2, Nanog, H19, and Igf2 genes a: The pluripotency genes (Oct-4, Nanog) expressions; b: The trophectoderm genes expressions ( Tead4, Cdx2), c: The imprinting genes expressions (H19, Igf2). 



\section{Figure 3}

Chimeric mice production. (a): injection of RAG1-knockout 129-mESCs cells (left) into 8-cell embryo (middle) and blastocoel (right). (b): Grade A (left) and Grade B (right) male chimeras generated from B6D2F1 embryos following manipulation and injection of RAG1-knockout 129-mESCs cell line into blastocoel. 


\section{a}



b
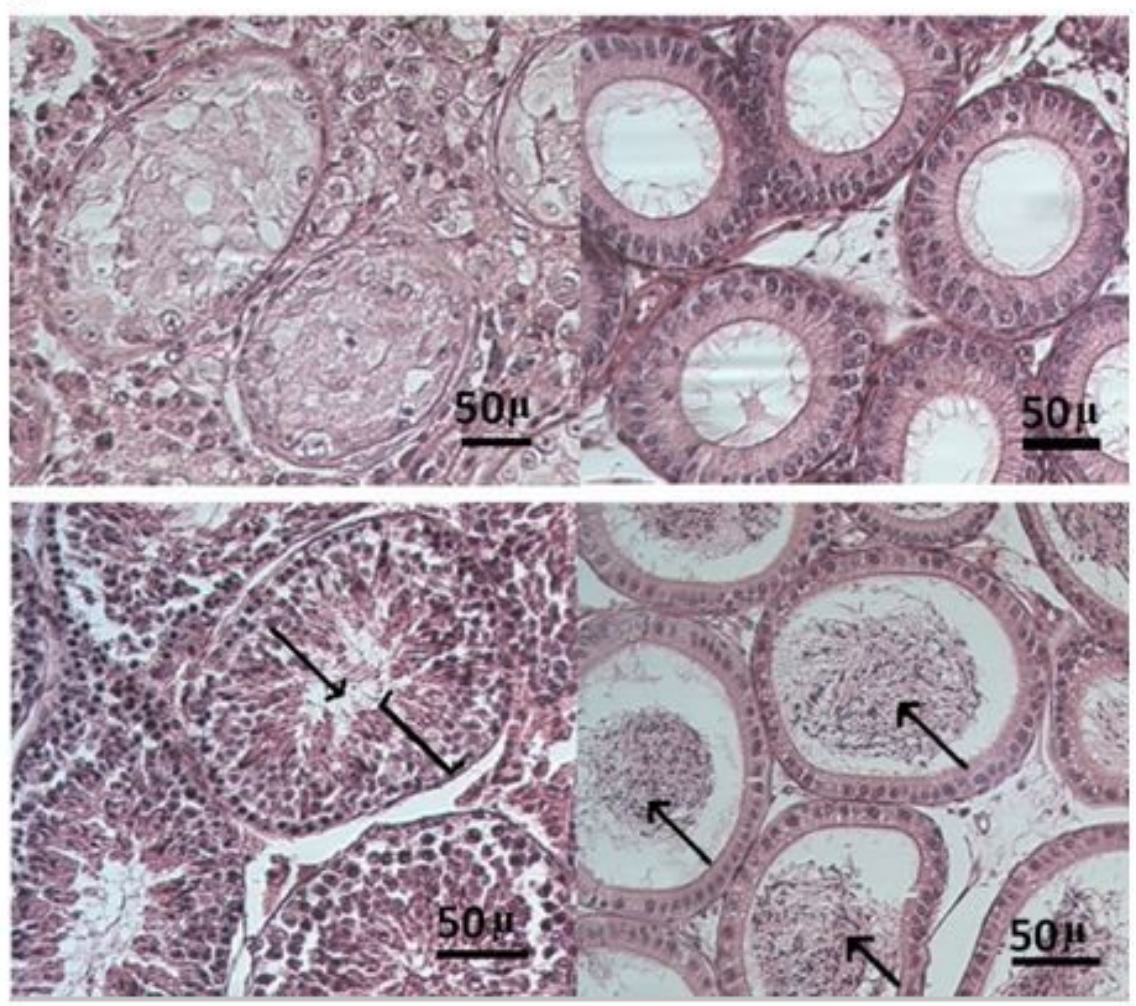

\section{Figure 4}

Genital tract of normal male mice and infertile male chimera. (a): The testes are shown with white arrows in the normal mouse (left) and with white circles in the infertile chimera (right) in which testes atrophy is quiet obvious. Vas deferens and epididymis components are apparently ordinary in normal male (left) and infertile chimera (right). (b): Hematoxylin-eosin stained testicular (left) and epididymal (righ) tissue sections in infertile male chimera (top row) and normal mice (bottom row). Compared with normal mice 
in which the germ cell layers in testes (marked with bracket) and sperms (marked with arrows) in the seminiferous tubules of epididymis are normal, in infertile chimera, testes and epididymis lack the germ cell layers and sperm, respectively.

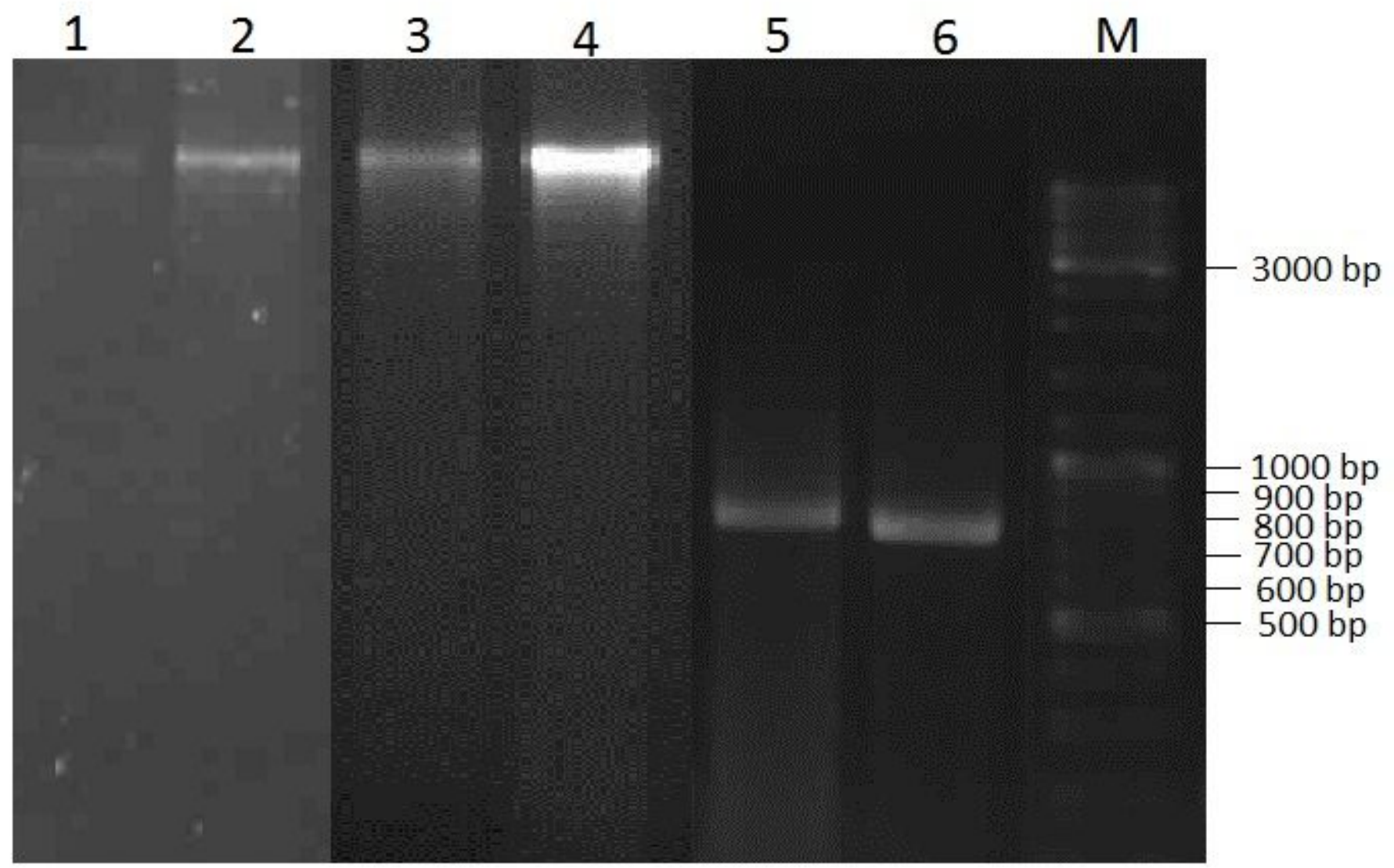

\section{Figure 5}

Electrophoresis results of genomic DNA extraction from C57BL/6 normal mouse sperm and PCR reaction of RAG1 gene. From the left, lanes 1, 2 and 3 are genomic DNA samples of 20,000, 100,000 and 300,000 sperm extracted from the vas deferens, respectively, and lane 4 is total genomic DNA isolated from the epididymis. The lanes 5 and 6 , respectively, were the PCR product of RAG1 gene ( $860 \mathrm{bp})$ with the DNA template from sample of 20,000 sperms and total sperm of epididymis, lane M: $1 \mathrm{~kb}$ DNA ladder. The gel images were edited and cropped in order to remove irrelevant aspects of the image and to centralize the results together; full-length gels are presented in supplementary figure S5.

\section{Supplementary Files}

This is a list of supplementary files associated with this preprint. Click to download.

- SupplementaryFigureS5.docx 